
средней доли легкого на фоне хронической обструктивной болезни легких. Клинический случай

\author{
О.П. Башмакова, Л.Н. Шилова, Е.Г. Черкесова, С.С. Хортиева \\ ФГБоу ВО «Волгоградский государственный медицинский университет» Министерства здравоохранения Российской федерации; \\ Россия, г. Волгоград
}

\title{
PEЗЮME
}

\begin{abstract}
Цель статьи: продемонстрировать сложности диагностики состояния пациента и терапии при осложненной внебольничной пневмонии на фоне хронической обструктивной болезни легких (ХОБЛ).

Основные положения. Внебольничная пневмония является одним из самых распространенных заболеваний. Особое внимание заслуживают пациенты, имеющие отягощенный коморбидный фон, так как у них больше факторов риска для неблагоприятного прогноза. В данной статье приведен случай осложненного течения внебольничной пневмонии на фоне ХОБЛ. Несмотря на выбор адекватной терапии, ввиду дополнительных отягощающих факторов у пациента развился острый абсцесс легкого, требующий хирургического вмешательства. Заключение. Своевременная диагностика и адекватная терапия в ранние сроки позволяют объективно улучшить состояние больного и его качество жизни, предотвратить развитие тяжелых осложнений.

Ключевые слова: пневмония, абсцесс, антибактериальные препараты, хроническая обструктивная болезнь легких.
\end{abstract}

Вклад авторов: Башмакова 0.П. - обследование и лечение пациента, сбор клинического материала, написание статьи; Шилова Л.Н. окончательное оформление статьи, проверка критически важного содержания, утверждение рукописи в печать; Черкесова Е.Г. интерпретация клинических и лабораторных данных, анализ литературных источников, оформление и написание статьи; Хортиева С.С. проверка критически важного содержания, обзор публикаций по теме статьи.

Конфликт интересов: авторы заявляют об отсутствии возможных конфликтов интересов.

Для цитирования: Башмакова 0.П., Шилова Л.Н., Черкесова Е.Г., Хортиева С.С. Внебольничная пневмония с исходом в абсцесс средней доли легкого на фоне хронической обструктивной болезни легких. Клинический случай. Доктор.Ру. 2021; 20(7): 73-76. DOI: 10.31550/1727-23782021-20-7-73-76

\section{Community-Acquired Pneumonia and Middle Lobe Abscess Associated with Chronic Obstructive Pulmonary Disease. A Case Study}

\author{
O.P. Bashmakova, L.N. Shilova, E.G. Cherkesova, S.S. Khortieva \\ Volgograd State Medical University (a Federal Government-funded Educational Institution of Higher Education), Russian Federation Ministry \\ of Health; 1 Pavshikh Bortsov Square, Volgograd, Russian Federation 400131
}

\section{ABSTRACT}

Objective of the Paper: To demonstrate the issues with diagnosis and therapy in complicated community-acquired pneumonia associated with chronic obstructive pulmonary disease (COPD).

Key Points. Community-acquired pneumonia is one of the most common diseases. Of special interest are patients with comorbidities, since they have more risk factors of poor prognosis. This article describes a clinical case of complicated community-acquired pneumonia associated with COPD. Despite an adequate therapy, the patient developed an acute middle lobe abscess requiring surgery, as the patient had confounding factors.

Conclusion. Timely diagnosis and an early adequate therapy allow improving the condition and quality of life of the patient and preventing severe complications.

Keywords: pneumonia, abscess, antibacterials, chronic obstructive pulmonary disease.

Contributions: Bashmakova, O.P. - patient examination and management, clinical material collection, text of the article; Shilova, L.N. approved final article version, review of critically important material, approval of the manuscript for publication; Cherkesova, E.G. - interpretation of clinical and laboratory data, literature review, approved and text of the article; Khortieva, S.S. — review of critically important material, review of thematic publications.

Conflict of interest: The authors declare that they do not have any conflict of interests.

For citation: Bashmakova 0.P., Shilova L.N., Cherkesova E.G., Khortieva S.S. Community-Acquired Pneumonia and Middle Lobe Abscess Associated with Chronic Obstructive Pulmonary Disease. A Case Study. Doctor.Ru. 2021; 20(7): 73-76. (in Russian). DOI: 10.31550/1727-2378-2021-20-7-73-76

Башмакова Ольга Павловна (автор для переписки) - аспирант ФГБоу ВО «ВолгГМУ» Минздрава России. 400131, Россия, г. Волгоград, площадь Павших Борцов, д. 1. еLIBRARY.RU SPIN: 7232-0450.E-mail: this_is_olga@mail.ru

Шилова Людмила Николаевна - Ә. м. н., доцент, заведующая кафедрой госпитальной терапии, военно-полевой терапии. ФГБоУ ВО «ВолгГМУ» Минздрава России. 400131, Россия, г. Волгоград, площадь Павших Борцов, д. 1. eLIBRARY.RU SPIN: 4950-2391. E-mail: ludshilova@mail.ru

(Окончание нас. 74.) 


\section{ВВЕДЕНИЕ}

Пневмонии - нозологическая единица, характеризующаяся острым инфекционным процессом, провоцирующим появление очаговых поражений в легких и развитие внутриальвеолярной экссудации ${ }^{1}$. Если болезнь возникла вне стационара, то первые 48 часов она считается внебольничной пневмонией [1]. Особенно часто она наблюдается как осложнение при ХОБЛ, которое может спровоцировать целый ряд тяжелых исходов и поставить под угрозу жизни пациентов [2]. Острый абсцесс легкого возникает при деструктивном процессе в паренхиме легкого с проявлением в виде гнойно-некротического очага, представленного ограниченной полостью. При несвоевременной диагностике, недооценке тяжести состояния или неадекватном лечении он может привести к летальному исходу [3]. В статье представлен клинический случай внебольничной пневмонии, осложненной абсцессом легкого. Несмотря на лечение антибиотиками с широким спектром действия и чувствительностью к выявленному микроорганизму, в указанном случае не удалось предотвратить осложнений.

\section{КЛИНИЧЕСКОЕ НАБЛЮДЕНИЕ}

Мужчина, 50 лет, поступил в клиническую больницу в августе 2018 года с высокой температурой тела -до $38^{\circ} \mathrm{C}$, кашлем с мокротой слизисто-гнойного характера, незначительной одышкой при физической нагрузке, болью в грудной клетке справа.

Из анамнеза пациента известно, что его здоровье ухудшилось в конце июля 2018 года (приблизительно за 10 дней до поступления в больницу), когда появились малопродуктивный кашель, боль в грудной клетке справа, усиливавшаяся на высоте вдоха. Мужчина обратился за медицинской помощью в поликлинику по месту жительства. Его осмотрел участковый терапевт: объективно было диагностировано жесткое дыхание, рассеянные сухие хрипы по всем легочным полям; другие показатели - без особенностей. Был поставлен диагноз ХОБЛ 2 стадии (по GOLD), группа A, с умеренно выраженными симптомами (САT - 5 баллов, mMRC - 1 балл), средней степени тяжести, в стадии обострения. Дыхательная недостаточность II степени. Наряду с бронхолитической терапией была назначена антибиотикотерапия: таблетированная форма амоксициллина и клавулановой кислоты в дозах 500/125 мг 3 раза в день. На фоне терапии сохранялась вышеописанная симптоматика, значительных изменений в состоянии пациента отмечено не было. При повторном осмотре в поликлинике к терапии был добавлен препарат фторхинолонового ряда, левофлоксацин, в дозе 500 мг по 1 таблетке 1 раз в день.

Через несколько дней пациент вновь обратился в поликлинику по месту жительства ввиду ухудшения состояния: температура тела поднялась до $38,5^{\circ} \mathrm{C}$, появились общая слабость, кашель с выделением мокроты вязкого характера, боль в грудной клетке справа, усиливающаяся при глубоком дыхании. Пациенту провели рентгенографию органов грудной клетки. По ее данным, в нижней доле правого легкого, в сегментах S8, S9, была отмечена интенсивная инфильтрация, правый корень был расширен, структурен, междолевая плевра уплотнена, синусы свободны, диафрагма оставалась в норме. Сердце и аорта - в пределах нормы. Заключение: правосторонняя бисегментарная пневмония в нижней доле. Ввиду отрицательной динамики состояния пациента, отсутствия положительного эффекта антибиотикотерапии и на основании полученных данных рентгенографии органов грудной клетки больной был направлен на стационарное лечение.

Из анамнеза жизни известно, что больной курил по пачке сигарет в день в течение 25 лет, периодически у него появлялся кашель, иногда с мокротой, обычно в первой половине дня. В 2016 году больному поставили диагноз ХОБЛ 2-й стадии, по GOLD, группа A, с умеренно выраженными симптомами (САT - 5 баллов, mMRC - 1 балл). Бронхолитические препараты (комбинация длительно действующего $\beta 2$-агониста с М-холинолитиком) использовал нерегулярно.

При поступлении в стационар пациент был в состоянии средней тяжести, кожа и видимые слизистые сохраняли обычную окраску. ИМТ = 29 (повышенное питание). Температура тела $-37,8^{\circ} \mathrm{C}$. Периферические лимфатические узлы увеличены не были. В костно-мышечной системе особенности не обнаружены. Грудная клетка была обычной формы. Отмечено глубокое дыхание, экскурсия правой половины грудной клетки из-за боли была ограничена, бронхофония и голосовое дрожание - без особенностей. При перкуссии легочных полей определялся коробочный звук, а в нижней доле справа было выявлено притупление. Аускультативно выявлялись жесткое дыхание, рассеянные сухие хрипы, справа дыхание было ослабленное; в правой нижней доле выслушивались крепитирующие хрипы. чДД - 21 в минуту, сатурация - 93\% в отсутствие кислородной поддержки. Пульс ритмичный, 86 ударов в минуту. Границы относительной тупости сердца не расширены, тоны сердца приглушены, ритмичны. ЧСС - 88 в минуту, АД 145/85 мм рт. ст. Отклонения от нормы в других системах организма не обнаружены. В общем анализе крови при поступлении наблюдался лейкоцитоз до 18,2 × 109 /л и ускоренный показатель СОЭ (32 мм/ч).

На основании жалоб, анамнеза, данных физикального обследования, лабораторных и инструментальных исследований был выставлен диагноз: ХОБЛ 2-й стадиu, no GOLD, группа A, с умеренно выраженными симптомами (САT 5 баллов, mMRC - 1 балл), средней степени тяжести, в стадии обострения по типу внебольничной правосторонней нижнедолевой пневмонии средней степени тяжести. Интоксикационный синдром. Дыхательная недостаточность II степени.

При поступлении пациенту назначили 1000 мг цефотаксима 2 раза в день в/в, 500 мг азитромицина 1 раз в день в/в капельно, инфузионную терапию с лекарственным раствором в дозе до 2000 мл в сутки с контролем диуреза, 30 мг амброгексала в таблетированной форме 3 раза в день первые два дня с последующим приемом 2 раза в сутки, бронхолитическую терапию через небулайзер (комбинацию

Черкесова Елена Григорьевна — к. м. н., доцент кафедры госпитальной терапии, военно-полевой терапии. ФГБОУ ВО «ВолгГМУ» Минздрава России. 400131, Россия, г. Волгоград, площадь Павших Бориов, д. 1. eLIBRARY.RU SPIN: 8528-8594. E-mail: elena.tcherkesowa@yandex.ru Хортиева Светлана Степановна - к. м. н., доцент кафедры госпитальной терапии, военно-полевой терапии. ФГБоу ВО «ВолгГмУ» Минздрава России. 400131, Россия, г. Волгоград, площадь Павших Борцов, д. 1. eLIBRARY.RU SPIN: 2009-0620. E-mail: sskhortieva@volgmed.ru (Окончание. Начало см. на с. 73.)

${ }^{1}$ https://minzdrav.midural.ru/uploads/clin_recomend\%20PФ.pdf 
ипратропия бромида в дозе 0,25 мг и фенотерола в дозе 0,5 мг 2 раза в день).

Через 72 часа у пациента сохранялись тяжелый интоксикационный синдром (утром температура $-38^{\circ} \mathrm{C}$, вечером $38,7^{\circ} \mathrm{C}$ ), малопродуктивный кашель, одышка. В общем анализе крови уровень гематокрита был снижен на $30 \%$, уровень гемоглобина - на 101 г/л, лейкоцитоз до 17,7 × 109/л, СОЭ увеличилась до 60 мм/ч, тромбоцитоз до $982 \times 10^{9} /$ л. В связи с отсутствием положительной динамики от терапии было принято решение о смене антибиотиков на меропенем в дозе 1000 мг 3 раза в день в/в капельно и раствор ванкомицина в дозе 1000 мг 2 раза в день в/в капельно.

В биохимическом анализе сыворотки крови гликемия составила 6,3 ммоль/л, СРБ повышенный - 105 мг/л, прокальцитониновый тест - менее 0,5 по референтным значениям.

Через 5 суток клиническая и лабораторная картины имели отрицательную динамику, поэтому было решено заменить антибиотикотерапию на раствор линезолида в дозе 600 мг 2 раза в день в/в капельно и раствор моксифлоксацина в дозе 400 мг 1 раз в день в/в капельно, также больному проводили симптоматическую и инфузионную терапию с применением 20\%-ного раствора альбумина в дозе 100 мл 1 раз в день в/в капельно - 12 доз.

Общий анализ мокроты: характер слизистый, вязкая, лейкоциты - до 30 в поле зрения. При бактериологическом исследовании мокроты выделена Klebsiella pneumoniae, которая имела чувствительность к меропенему, гентамицину, амикацину, сохраняла устойчивость к ципрофлоксацину, левофлоксацину, цефтазидиму, цефотаксиму, амоксициллину/клавуланату, ампициллину, цефепиму.

При повторной рентгенографии органов грудной клетки на 5-е сутки была отмечена отрицательная динамика: справа - осумкованная жидкость до IX ребра по лопаточной линии, в нижне-заднем отделе над диафрагмой, с инфильтрацией легочной ткани в сегментах S8, S9, S10, S4, S5. Передний синус запаян, корень расширен, малоструктурен, слева инфильтрации и очагов нет; тень сердца расширена в поперечнике влево, аорта расширена.

Пациенту было проведено КТ легких на 6-е сутки пребывания в стационаре для верификации абсцесса в паренхиме легочной ткани. В легочных сегментах S7, S8, S9, S10, S3, S6 выявлена плотная интерстициально-альвеолярная инфильтрация легочной паренхимы с симптомом воздушной бронхографии смешанного типа, с утолщенной до 1 см подлежащей париетальной плеврой. Легочные поля были эмфизематозны. Данных об абсцессе легких нет (рис.).

Пациент провел в терапевтическом отделении 10 суток. Результаты анализов были следующие: тромбоциты $683 \times 10^{9} /$; ; лейкоциты $-24,3 \times 10^{9} /$ л; гематокрит $-27,6 \%$; гемоглобин - 94 г/л; нейтрофилез: п-7\%, с-76\%, л-11\%, м-5\%, э-1\%; СОЭ - 59 мм/ч; анизоцитоз с преобладанием макроцитов; анизохромия эритроцитов; пойкилоцитоз эритроцитов, 2-3 в поле зрения. Динамика биохимического анализа крови оставалась без существенных изменений, кроме значения альфа-амилаза - 71,6 ед/л, СРБ - 100 мг/л. Коагулограмма: протромбиновое время - 18,3 в секунду, фибриноген - 2,0 г/л, активированное частичное тромбопластиновое время - 33,0 в секунду, в динамике без изменений. Рентгенография органов грудной клетки в боковой проекции показала затемнение, жидкость и газ в сегментах S4, S5; толщина стенок была до 1,5 cм, были видны четкие контуры, корень на этом фоне малоструктурный, слева - без осо-
Рис. КТ мегких: участки затемнения

интерстициально-альвеолярная инфильтрация

мегочной паренхимы смешанного типа.

A — поперечные срезы. В - реконструкция

в сагитта^ьной плоскости

Fig. Lung CT scan: opacity, mixed interstitial alveolar infiltration in lung parenchyma. A - cross sections. B sagittal plane reconstruction
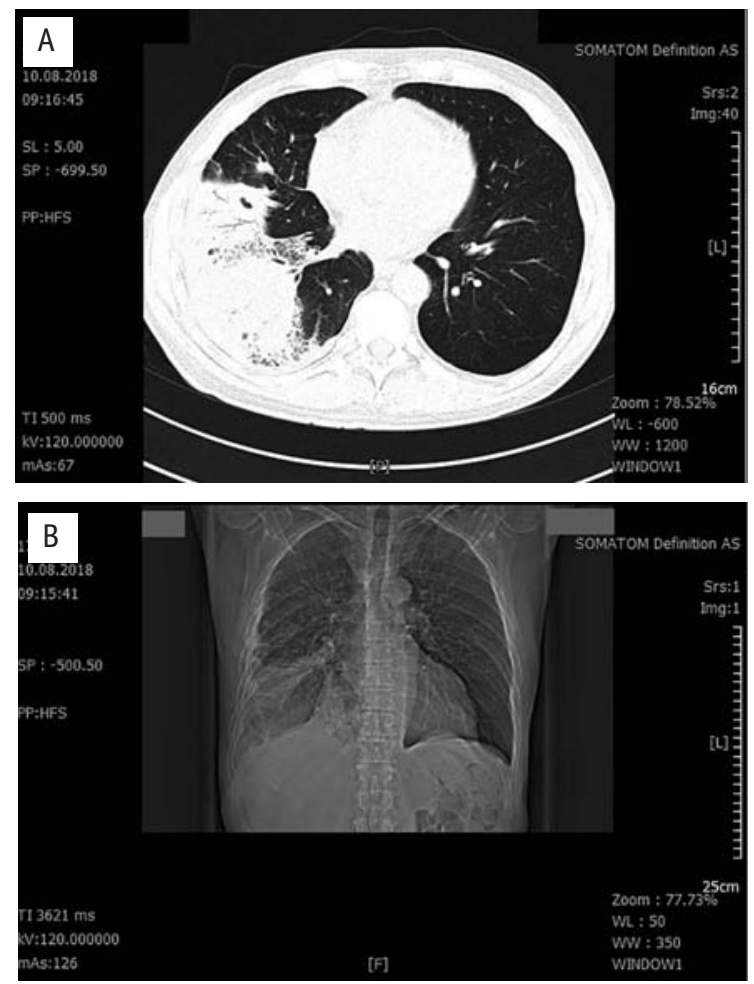

бенностей. Внебольничная пневмония у пациента осложнилась абсцессом в средней доле правого легкого.

Клинический диагноз: Внебольничная правосторонняя полисегментарная нижнедолевая пневмония тяжелой степени, осложненная абсцессом средней доли правого легкого. Дыхательная недостаточность II степени. Интоксикационный синдром. ХОБЛ 2-й стадии (группа $A$, nо GOLD) смешанного фенотипа, с умеренно выраженными симптомами (САT - 5 баллов, $m M R C-1$ балл), средней степени тяжести в стадии обострения.

Пациент был переведен в торакальное отделение, где консилиум определил тактику и объем хирургического вмешательства. Пациенту провели нижнедолевую лобэктомию правого легкого. На 5-й послеоперационный день был удален дренаж из плевральной полости. В течение 5-ти дней пациент проходил курс антибактериальной профилактики. Послеоперационный период протекал без осложнений. Рана зажила первичным натяжением. На контрольной рентгенографии видно смещение средостения в оперированную сторону, визуализируется линия скобочного шва, очаговых и инфильтративных теней не выявлено.

Пациент был выписан на амбулаторное лечение в стабильном состоянии с рекомендациями по дальнейшему использованию бронхолитической терапии (сочетания олодатерола в дозе 2,5 мкг и тиотропия бромида в дозе 2,5 мкг по 2 вдоха 1 раз в день) и контролю ФВД. На амбулаторном этапе (через месяц после операции) было проведено исследование ФВД, которое не показало выраженного снижения 
динамических показателей: ЖЕЛ снизилась с 96\% до 88\%, ФЖЕЛ - с 88\% до 83\% и ОФВ - с $76 \%$ до 73\% до операции и после операции соответственно. Потери ОФВ после операции не превысили более 5\% (от предоперационного). Таким образом, резекция нижней доли правого легкого не привела к прогнозируемому снижению показателей ФВД и, соответственно, к снижению качества жизни.

\section{ОБСУЖДЕНИЕ}

В описанном выше клиническом случае у пациента на фоне внебольничной пневмонии наблюдалось развитие осложнения в виде абсцесса средней доли правого легкого. Развитие такого осложнения может быть обусловлено несколькими факторами, такими как возраст пациента, сопутствующая патология (СД, ИБС, ХОБЛ, метаболический синдром и т. д.), сочетание которых в совокупности создает фон для неблагоприятного отягощающего течения заболевания. Ряд проведенных ранее исследований говорит о неблагоприятном течении внебольничной пневмонии у пациентов с ХОБЛ, и в 27,5\% случаев отмечают тяжелое течение с неблагоприятным исходом [2]. Развитие инфекций у больных с ХОБЛ является частой причиной обострений. Достаточно редким, но грозным осложнением является абсцесс легкого. Среди пациентов, имеющих неблагоприятный коморбидный фон, в структуре возбудителей, вызывающих развитие абсцесса легких, преобладают грамотрицательные микроорганизмы: Klebsiella, Escherichia coli, Proteus, Pseudomonas aeruginosa, а также стафилококки и неклостридиальные анаэробные микроорганизмы. У пациентов с хронической легочной патологией, которым нередко требуется стационарное лечение обострений, наиболее часто встречается грамотрицательная флора. У больного в процессе обследования был выявлен грамотрицательный микроорганизм K. pneumoniae, который имеет большой спектр резистентности. Поэтому лечение абсцесса легких является трудной задачей ввиду высокой частоты резистентных штам-

\section{ЛИТЕРАTУPA / REFERENCES}

1. Пушникова С.В. Особенности клинического течения и коагуляционно-тромбоцитарного гемостаза у больных с метаболическим синдромом и внебольничной пневмонией. Диссертация на соискание ученой степени кандидата медицинских наук. ГоУ ВПО «Тюменская государственная медицинская академия». 2009. [Pushnikova S.V. Clinical progression and coagulativethrombocytic hemostasis in patients with metabolic syndrome and community-acquired pneumonia. Candidate of Medicine Thesis. Tyumen State Medical Academy. 2009.(in Russian)]

2. Дворецкий Л.И. Внебольничная пневмония у больных хронической обструктивной болезнью легких. Практическая пульмонология. 2015; (2): 17-24. [Dvoretskiy L.I. Community-Acquired мов и неудовлетворительных исходов заболевания. К сожалению, анализ был проведен только в стационаре, поэтому теперь понятно, что первоначальная антибиотикотерапия была не совсем специфичной. Согласно данным литературы, наличие коморбидного фона (ХОБЛ, метаболического синдрома) часто становится предиктором неблагоприятного исхода воспалительного процесса [1, 2]. С учетом тяжелой сопутствующей патологии и отсутствия положительной динамики необходимо было изначально лечить больного в условиях стационара. Кроме того, на развитие заболевания могло повлиять и позднее обращение пациента (приблизительно на 10-й день от начала заболевания), и запоздалое рентгеновское обследование, которое надо было провести сразу при повторном обращении пациента с жалобами на отсутствие улучшения на фоне проводимой терапии.

\section{ЗАКЛЮЧЕНИЕ}

Для диагностики тяжелых пневмоний недостаточно уже известных лабораторных биомаркеров. Необходимы дополнительные маркеры для прогнозирования деструктивной пневмонии. В настоящий момент ведется их поиск. Так, например, в литературе присутствуют данные о возможном использовании фетуина-А как маркера деструктивного поражения. В исследовании R.P. Janapatla и соавт. 2016 года [4] указано, что низкий уровень фетуина-А является высокочувствительным предиктором к появлению деструктивной пневмонии у детского населения. У взрослых приведенные выше аспекты требуют дальнейшего изучения.

При выборе тактики ведения больных с внебольничной пневмонией в каждом случае надо учитывать индивидуальные особенности пациента, сопутствующую патологию, что позволит назначить адекватную терапию и предупредить развитие тяжелых респираторных осложнений, угрожающих жизни пациента, и объективно улучшить состояние больного и качество его жизни.

Pneumonia in patients with chronic obstructive pulmonary disease. Practical Pulmonology. 2015; (2): 17-24. (in Russian)]

3. Семенова Р.И., Сейдуманов М.Т., Мухамбетова Р.У. и др. Диагностика и лечение острого абсиесса легкого (случай из практики). Вестник Казахского Национального медицинского университета. 2015; (4): 378-80. [Semenova R.I Seydumanov M.T., Mukhambetova R.U. et al. Diagnosis and management of an acute pulmonary abscess (case study). Vestnik KazNMU. 2015; (4): 378-80. (in Russian)]

4. Janapatla R.P., Hsu M.-H., Liao W.-T. et al. Low Serum Fetuin-A as a Biomarker to Predict Pneumococcal Necrotizing Pneumonia and Hemolytic Uremic Syndrome in Children. 2016; 95(13): e3221. DOI: 10.1097/MD.0000000000003221 D 